\title{
Sport, fitness, and lifestyle entrepreneurship
}

\author{
Paul Jones ${ }^{1} \cdot$ Vanessa Ratten ${ }^{2} \cdot$ Ted Hayduk $^{3}$ \\ Published online: 1 May 2020 \\ (C) Springer Science+Business Media, LLC, part of Springer Nature 2020
}

\section{Introduction}

With the improvement of living conditions in many parts of the developing world, more people than ever before have the time, money, and access to invest in sport, physical activity, and wellness (Jones et al. 2017b). Additionally, increased connectivity and information sharing has empowered those around the globe to learn more about the importance of physical fitness, health, and emotional wellness, and to understand how access to participatory sport impacts those elements of life. Therefore, these industrial sectors are ripe for entrepreneurship and innovation, and along with it, rigorous academic research (Jones et al. 2019). Entrepreneurship holds immense potential as a driver of economic advancement and social progress (Drucker 1985). As a result of this potential, its tenants have been applied to several contexts - with sport highlighting special promise as an entrenched cultural phenomenon (Smith and Westerbeek 2007).

So far, most of the work has focused on sport-based entrepreneurship (Ratten 2011), but plenty of further research is required related to how sport entrepreneurship interacts and co-exists with the fitness and lifestyle sectors. In general, there is a need for scholarship and practical examinations that further map how entrepreneurship can be applied to the fitness and lifestyle industries (Jones and Jones 2014; Ratten 2011). Therefore, the aim of this special issue of International Entrepreneurship and Management Journal is to focus on how sport entrepreneurship is related to fitness and lifestyle entrepreneurship. The secondary aim is to outline how these sectors coproduce tenable opportunities for practical entrepreneurship as well as entrepreneurship

Paul Jones

W.P.Jones@Swansea.ac.uk

Vanessa Ratten

v.ratten@latrobe.edu.au

Ted Hayduk

ted.hayduk@nyu.edu

1 Swansea University, Swansea, UK

2 La Trobe University, Bundoora, Australia

3 New York University, New York, NY, USA 
research. By working toward these goals, this special issue contributes to the development of sport entrepreneurship by highlighting the way fitness fits into individuals' lifestyle choices, how those choices affect their overall quality of life, and how those choices are being shaped by cultural and social trends (Jones et al. 2017a). Furthermore, this special journal issue is the first to explicitly focus on how sport, fitness and lifestyle entrepreneurship need to be integrated with the goal of advancing the broader entrepreneurship literature. Before we discuss the importance of sport entrepreneurship, we would like to sincerely thank Professor Dr. Salvador Roig for his support and expert guidance with this special journal issue.

\section{Entrepreneurship and sport}

Entrepreneurship as defined initially by Schumpeter (1934) involves the recognition of commercial value in a new invention and then using it to extract additional value from a market. Other conceptualizations stress that market shocks and cycle disruptions present unique opportunities for entrepreneurship because these conditions create uncertainty and risk, meaning entrepreneurs willing to shoulder additional hazard can reap greater rewards (Lerner 2010). Finally, many definitions of entrepreneurship have stressed that proactivity is central (Matsuno et al. 2002), implying that entrepreneurs extract outsized value by acting before their competitors. These themes have been applied in many contexts to generate a range of entrepreneurship subcategories, such as social entrepreneurship (Shapero and Sokol 1982), environmental entrepreneurship (Dean and McMullen 2007), female entrepreneurship (Minniti 2010), political entrepreneurship (Sheingate 2003), and educational entrepreneurship (Hess 2007). All of these forms of entrepreneurship are becoming increasingly important for their respective domains because entrepreneurship acts as a driver of growth and institutional change (Sheingate 2003).

Of the many contexts to which entrepreneurship has been applied, sport is proving an especially fruitful area for research (Ratten and Ferreira 2016). Globally, the sport industry contributes to the economic growth and productivity of regions and nations (Pedersen and Thibault 2018; Ratten 2011). The global spend on sport and sport-related products is estimated at between $\$ 600$ billion USD and $\$ 1.3$ trillion USD (Pedersen and Thibault 2018). This estimate is exclusive of revenue from sports gambling, as legislation around this activity varies wildly by region and is only recently been loosened in the world's largest markets (e.g., North America and, specifically, the United States).

Beyond size, several aspects of the sport industry are unique and enable this process to occur. At its core, sport is an activity common to all cultures and periods, meaning it has a significant place in the hearts and minds of all societies (Smith and Westerbeek 2007). Furthermore, sport consumption is ephemeral in that contests can never be repeated. The core sport product is also unpredictable, as the quality of games and contests cannot be guaranteed. Further, the value chain for sport's core product is instantaneous - with production, distribution, and consumption occurring simultaneously. As a result of these unique industry dynamics, many have speculated that sport is an ideal space in which to learn about entrepreneurial phenomena, because these environments are thought of as more universal, faster paced, shorter-lived, and less predictable than traditional business environments. Relatedly, scholarship has 
suggested that individuals who are successful in sport or entrepreneurship are likely to be successful in the other due to a set of personality traits that are advantageous to both (i.e., meritocratic, competitive drive, iterative learning style, comfort with fast-paced ecosystems). Essentially, sport offers an ideal laboratory for the study and advancement of entrepreneurial theory and analysis.

Because of the inherent similarities between sport and entrepreneurship, individuals, businesses, and governments are becoming interested in the ways sport can be leveraged for innovation and entrepreneurship. This philosophy has been termed sport based entrepreneurship (Ratten 2010), and it has rapidly gained acceptance as a legitimate sub-area of entrepreneurship and innovation management research. Ratten (2011) described sport entrepreneurship as inherently interdisciplinary, and defines the framework as "any form of enterprise or entrepreneurship in a sports context" (p. 60). Therefore, sport-based entrepreneurship can take a variety of forms. One example involves a group of individuals starting a new sport venture. Consider the trajectory of daily fantasy sports. Entrepreneurs Nigel Eccles, Tom Griffiths, and Lesley Eccles founded FanDeul in 2009, while Jason Robbins, Paul Liberman, and Matther Kalish founded DraftKings in 2012. Together, these two platforms led the way in developing innovative fantasy sports betting formats that shortened betting cycles from a whole season to just 1 week or even a single day. In doing so, they fundamentally altered the way fantasy sports betting is conducted, placing a newfound emphasis on short-term returns.

Sports entrepreneurship can also be practiced by businesses and governments who attempt to leverage the international exposure of sport mega events (SMEs). Saxton (2016) describes how the Olympics have been an opportunity to showcase entrepreneurship and innovation - from 'cupping', a therapeutic treatment received by athletes, to aerodynamic cycling gear, Gatorade and other sports drinks, and Roger Bannister's interval and lactate threshold training methods. Spilling (1996a, b) described how a host-nation's institutional networks could interact to grow the collective entrepreneurial capacity. Spilling noticed that an 'entrepreneurial system' was the central driver of economic successes documented during the 1994 Lillehammer Olympics. Spilling describes how local business ecosystems and individuals acted creatively and proactively, while shouldering additional risk, to procure resources required for the event. In so doing, the author describes how this underlying entrepreneurial system is the bedrock of regional economic development and how it can be enhanced by hosting a SME. Developing and developed regions commonly differ in the prevalence of 'necessity' and 'opportunity' entrepreneurs. Opportunity entrepreneurs are individuals who start a business because they perceive an opportunity and have the resources at their disposal to pursue it such as personal networks, capital, technological knowledge and access. Opportunity entrepreneurs are common in developed economies, which have greater access to and dispersion of these important resources. Additionally, developed nations typically have strong institutional and governmental resources in place that serve to provide social safety nets for entrepreneurs whose businesses fail. On the contrary, developing nations are more typically associated with necessity entrepreneurs, who enter into business for themselves because they simply have no other choice. Developing nations are characterized by the absence of equitable access to financial capital, property rights, business freedoms, labour rights, and educational resources - and as such individuals have fewer options for employment. 
With this important distinction as a foundation, it should be clear that theories and practice of sport-based entrepreneurship may 'look' significantly different between various geographical contexts - perhaps especially between developing and developed nations. Thus, sport based entrepreneurship may be viewed as a series of successive components or stages within a process model, where sport is the central underlying driver. At one end of the process, developing nations require basic capital, physical, and institutional resources that are known to stimulate creativity and risk-taking. On the other end of the model, developed nations require the optimization and re-combination of factor inputs and institutional resources, which serves to further enhance its innovative capacity and entrepreneurial throughput.

In addition to creativity and innovation originating from outside the boundaries of large firms, another example of sports entrepreneurship is large companies using sport to catalyze their 'interpreneurship' efforts. Intrapreneurship is a term that applies entrepreneurship philosophies within the context of a large (typically inertial) organization (Antoncic and Hisrich 2003). Google, Amazon, and Twitter have all used sport entrepreneurship in their quest to distribute live sport content on their worldwide digital networks. In short, these communications networks have used sport content distribution as a catalyst to develop interest in their complete slate of 'over the top' (OTT) offerings (e.g., digital network architecture that bypasses physical infrastructures). As a result, the next generation of sport content distribution rights will likely shift from traditional television broadcasters to OTT providers (Bozek et al. 2017). This method of consumption will be important for connecting sport consumers who are increasingly spread out geographically. The digital nature of these platforms also produces a more immersive consumption experience, allowing consumers to interact and share their reactions to game content in real time with one another using text, audio, and video modalities. These new experiential features, which could previously only be obtained via in-person group consumptive modalities, can now be digitally re-created irrespective of physical location. The benefits of these digital, immersive experiences will benefit teams and leagues who are both (a) digitally-native and (b) digitallyaugmentative (that is, they use digital experiences as an ancillary component to their core, non-digital product). Digitally native professional leagues, such as the newly established Premiere Lacrosse League (PLL), will be able to leverage these platforms to amass robust networks of consumers who predominantly search for and engage with content on digital touchpoints on Instagram, Twitch, Facebook, Reddit, and others.

Another stakeholder group that is currently benefitting from is fragmenting market for content is individual athletes. More than ever, individual athletes have realized the importance of building a personal brand and leveraging that brand for economic and social gain (e.g., Ratten 2015). The most popular athletes regularly have followings that vastly outnumber the teams and leagues that employ them - examples include LeBron James, Neymar, Lionel Messi, and Cristiano Ronaldo. Their large social media presence has enabled them to earn entrepreneurial rents. For example, Lebron James' following has enabled him to earn approximately $\$ 300,000$ per sponsored post on Instagram via his laundry list of partners: GMC, Nike, Ladder Sport, Hummer, and others.

Social media and OTT streaming is also benefitting less recognizable athletes, as well. In the past, only the most popular athletes were capable of garnering enough social capital and recognition to earn an income from endorsements. However, athletes 
of all stripes can now connect with individual sport consumers, and they can do so at previously unimaginable scale. Currently, athletes at lower tiers of competition, or athletes in sports that typically receive minimal media attention, are building followings in the tens or hundreds of thousands, which can be directly leveraged to earn sponsorships, partnerships, and endorsements. A central example of this phenomenon is eSport athletes and enthusiasts who live stream their content on Twitch.

In all of these scenarios, actors attempt to extract additional value from an uncertain market using the power and influence of sport as the catalyst. Therefore, it is important to remember that sport based entrepreneurship expands beyond the commercial sector to include both the public and nonprofit sectors.

\section{Sport, fitness, and lifestyle entrepreneurship}

Due to the physical demands of sport participation, the sport industry is often linked to the fitness and lifestyle sectors (Ratten 2012). As with sport, the lifestyle and fitness sectors have been described as unique environments for deploying entrepreneurial thinking and creative business strategies. For one, lifestyle and fitness are both rooted in hospitality, which is an industry predicated on small business entrepreneurship (Peters et al. 2009). Lifestyle entrepreneurship is specifically defined by Henricks (2002) as entrepreneurship that is driven by personal beliefs, values, morals, and passions. While having a desire to earn a living, what lifestyle entrepreneurs desire most is balance between work that does not violate their ethics and morals, time with family and friends, community engagement, and the pursuit of hobbies and ancillary interests (Henderson 2002). In their pursuit of such balance, lifestyle entrepreneurs place great emphasis on health of mind, body, and spirit. Lifestyle entrepreneurs such as Greg Glassman, John Collins, and Chip Wilson founded CrossFit, Ironman, and Lululemon, respectively. They were motivated by their individual passions for health and wellness and were driven to provide access to and knowledge of functional fitness and comfortable, high-quality athletic wear. From this definition and examples, the conceptual relatedness of lifestyle entrepreneurship to fitness entrepreneurship (e.g., entrepreneurship driven by the philosophy of holistic health and wellness) becomes quite clear.

The internationalization of the sport industry has meant that lifestyle habits related to fitness are constantly evolving (Huertas González-Serrano et al. 2020). Specifically, there has been increased effort devoted to positioning participatory sport as a centerpiece of one's lifestyle choices and fitness goals, rather than a casual activity reserved only for leisure time (Heywood 2015). With individuals now completely immersed in sport and fitness participation, innovations abound that provide opportunities to engage in new kinds of fitness. There is now a large market for participatory sports such as CrossFit, Ironman, Tough Mudder, Spartan Race, yoga, marathons, and triathlons (Ratten and Ferreira 2017). This interest both drives and coincides with advanced media technologies that disseminate information regarding competitions and contests (Ratten and Jones 2018).

Importantly, fitness and the pursuit of work-life balance have been aided by the advent of new technologies. Fitness enthusiasts and sport participants require greater convenience, socialization, product quality, and affordability now than ever before. Entrepreneurial individuals and companies have responded to these shifts in lifestyle 
demands using technology. The innovations they have created span a range of industries. For example, active wear has been designed that resists damage specific to functional fitness and exposure to harsh elements (e.g., Lululemon, Rogue, Hylete, Rhone, etc.). Wearable technologies like Fitbit and Apple Watch now assist athletes track and obtain physiological and biometric feedback. There are telephone applications like Strava that enable athletes to connect with other enthusiasts, share tips, track workouts, and even receive remote coaching. Cryogenic therapy chambers sold by CryoUSA are being distributed en masse for use in muscle recovery and circulation. A range of newly developed dietary supplements marketed and sold by companies like NutraScience and Nutrabolt are making access to nutrition management and niche supplements easier than ever before. Websites like WellnessFX help consumers gain insight into their nutrition and dietary needs using blood tests. Last, targeted exercise classes like Barre, Pilates, Zumba, and Boxing appear in waves, and are designed to meet very specific fitness and lifestyle objectives.

\section{Overview of articles in the special journal issue}

This special journal issue consists of eight articles that were double blind peer reviewed. The first article is titled 'Sport entrepreneurship: A synthesis of existing literature and future perspectives' by Massimiliano Pellegrini, Riccardo Rialti, Giacarmo Marzi and Andrea Caputo. As sport entrepreneurship is a relatively new field, this article provides a basis from which to understand the drivers of entrepreneurship in a sport context. The article traces the development of sport entrepreneurship from a cultural and historical perspective by focusing on the key contributions sport plays to global economic development. This enables the identification of reasons why entrepreneurship is so important to the overall functioning of the sport industry. The existing literature on sport entrepreneurship is analysed with the following key themes identified: theoretical perspectives, pedagogical approaches and social benefits. This enables some suggestions about future research paths to be made. The second article titled 'Entrepreneurial Orientation in Sports Entrepreneurship - A Mixed Methods Analysis of Professional Soccer Clubs in the German-Speaking Countries' is by Jonas Hammerschmidt, Fabian Eggers, Sascha Kraus, Paul Jones and Matthias Filser. This article fills a gap in the current sport entrepreneurship research by analyzing the relationship between entrepreneurial orientation and performance. This contributes to a improved understanding regarding the role of entrepreneurial orientation, organizational performance and coopetition in sport. By focusing on soccer clubs, the study provides a way to understanding how entrepreneurship influences sporting performance. Thereby highlighting the need for an entrepreneurial orientation in sport.

The third article is titled 'Professional athletes exhibit favourable characteristics for entrepreneurship- especially in high risk sports' by Kathrin Steinbrink, Elisabeth Berger and Andreas Kuckertz. Athlete entrepreneurs provide important role models in society in terms of leadership and innovative capabilities. This article highlights how many athletes have an entrepreneurial intention that impacts their sporting success. Thereby taking a person-job fit theory to the literature on sport entrepreneurship. As few current studies exist on athlete entrepreneurs, this study provides a good foundation for understanding entrepreneurial behavior based on type of sport played. This enables an examination of how entrepreneurship is often a second or dual career for athletes. 
The article highlights how there needs to be more entrepreneurship education in the sport industry.

The fourth article is titled 'Performative entrepreneurship: Identity, behaviour and place in sports enterprise' by Stephen Dobson and Pete McLuskie. This article focuses on the entrepreneurial nature of adventure sports. This enables a performative entrepreneurship lens to be applied to a study of mountain bike trainers and guides. This is a new approach to understanding the community benefits derived from sport entrepreneurship. Mountain biking is a sport that has received scant attention in the literature so this study provides a novel approach to the variety of sports that can be studied from an entrepreneurial perspective. Thereby contributing to the field of lifestyle entrepreneurship and the role of the natural environment. This enables a improved understanding about the role less formal sports play in developing entrepreneurship.

The fifth article is titled 'Looking for God, meaning, physical fitness and beyond: The religious and spiritual space in sport entrepreneurship' by Nuria Toledano. This article provides a philosophical understanding for the linkage between sport participation and lifestyle factors. Thereby capturing the way religion and spirituality influence sport entrepreneurship. This is important particularly in lifestyle sports that offer a more spiritual way to participate in sport. Due to the increasing influence of lifestyle sports such as yoga and meditation, this article paves the way for more emphasis on slow fitness. This is helpful in bridging the gap between religion, spirituality and sport.

The sixth article is titled 'I just want to surf, make boards and party: How do we identify lifestyle entrepreneurs within the lifestyle sports industry?' by Laura Wallis, Andreas Walmsley, Emily Beaumont and Carole Sutton. This article focuses on the role lifestyle entrepreneurs play in economic and societal development. Due to the relative recent emergence of lifestyle entrepreneurs in the sport entrepreneurship literature, there is still much to know about this phenomenon. As a consequence, this article brings a new perspective into the sport entrepreneurship field by suggesting that lifestyle entrepreneurs can be classified as engagers or enablers. This is a useful way to understand the development role lifestyle entrepreneurs play in the sport ecosystem. Thereby it enables the literature to advance in terms of linking lifestyle motives to entrepreneurial intentions.

The seventh article titled 'Impact of lifestyle oriented motivation and corporate social responsibility on multiadventure sports firms performance' is by Maria Gonzalez-Serrano, Josep Hervas, Irena Valantine, Manuel Dos Santos and Ferran Calabuig Moreno. This article discusses the reasons why individuals become lifestyle entrepreneurs by highlighting the impact of corporate social responsibility. A sample of multi-adventure sport entrepreneurs is used to understand the objective and subjective performance rates. This enables an improved understanding of why lifestyle is important in establishing a sport business.

The eighth article is titled 'Sport entrepreneurship, digital transformation and knowledge management: Future research directions for value co-creation' by Vanessa Ratten and Paul Jones. This conclusion article to the special journal issue discusses the future of sport entrepreneurship research. The role of digital transformation in sport is highlighted in terms of the creation of new business ventures. In addition, the impact of digital transformation on knowledge management in sport is stated. This means that there needs to be more emphasis on value co-creation in sport entrepreneurship. 


\section{Next steps for sport, fitness, \& lifestyle entrepreneurship research}

Due to the prevalence of these sectors and their ties to social, cultural, and economic well-being, there is a significant need to conduct research that investigates the health, wellness and fitness aspects of sport that are driving innovation and entrepreneurship (Hayduk and Walker 2018). On a broad scale, there is still much to learn regarding how sport based entrepreneurship interacts with personal fitness and lifestyle factors. In addition, there is a need to uncover how and why sport based entrepreneurship differs from fitness and lifestyle-driven entrepreneurship. Within these theoretical avenues, work should focus on several specific research questions and themes.

First, the parallels between fitness and entrepreneurship have been explored, but only tangentially. Small businesses whose owners engaged in physical exercise like running, for example, were associated with improved sales performance (Goldsby et al. 2005). Overall, there is a general acknowledgement in academic circles that fitness and sport participation can be generative of positive business and career-related outcomes. Moreover, Rehman and Frisby (2000) and Hemme et al. (2017) both assessed outcomes associated with an entrepreneurial career path within sport, finding that personal trainers and gym owners demonstrated signs of both empowerment and marginalization as a result of becoming a fitness entrepreneur. However, in general little has been done to explicitly attach an entrepreneurship perspective to the management of the fitness sector (Goldsby et al. 2005; Ratten 2011). For example, the fitness industry, which is characterized as intensely cyclical, is perhaps an ideal environment for examining and testing entrepreneurship phenomena related to iteration, rapid prototyping, and agile management. Furthermore, the rapid adoption of virtual coaching is an important case study in digital disruption, as fitness consumers no longer have to attend a gym or seek out a personal trainer in their immediate geography. Related to digital disruption, understanding how technologies have increased access to fitness is an interesting area for future exploration (Ferreira et al. 2020). Social media and phone applications have democratized knowledge related to biomechanics and kinesiology, providing a significant foothold for individuals to get started on their fitness and/or sport participation journey (Ratten 2019). Artificial intelligence and machine learning have also been recently deployed to help athletes record their movements and compare their biomechanics against the optimal movement, with the goal of helping the athlete avoid injury and enhance longevity.

Similarly, exploring how technology has helped blend sport participation with fitness and lifestyle choices is another area worth exploration. Media and digital production companies have enabled entrepreneurs to create captivating and interactive fitness-centric experiences such as Spartan Race, CrossFit, Tough Mudder, and Peloton. Scholarship here could focus on understanding how participants use technology to build a self-concept rooted in sport participation and fitness. Likewise, understanding how technology can create sport participants and fitness enthusiasts who are 'overidentified' with a particular activity is equally important (Miragaia et al. 2019). These individuals run the risk of disassociating themselves with other elements of their selfconcept such as 'employee', 'parent', or 'spouse' in pursuit of goals related to their identification as an athlete. Thus, being mindful of this exposure and helping participants develop a well-rounded self-image that augments self-esteem while also attaining 
emotional balance will be important for fitness and lifestyle entrepreneurs (Ratten and Miragaia 2020).

Another focus in this domain would explore how individuals and businesses leverage next-generation technologies to deliver sport and fitness products to consumers in ways that are more interactive, social, and relationship-driven (e.g., as opposed to purchase-driven). Technologies like Snapchat, Twitter, and Instagram have allowed new and entrepreneurial sport brands to cultivate a sense of authenticity by posting content that followers want to interact with. As a result, these platforms have brought relationship marketing into the modern era and legitimized this approach to doing business in sport (Williams and Chinn 2010). This runs counter to the traditional methods of marketing and public relations, which focus on driving economic transactions (i.e., purchases). In that way, entrepreneurial brands create and leverage a marketing strategy built on two-way communication, while legacy approaches lag behind and struggle to gain acceptance among sport and fitness consumers. Learning how the former approach can be used to extract additional value from the fitness and lifestyle industries is a valuable area of future work.

Additionally, work in this area will need to investigate how sport based innovations and technologies have affected consumers' ability to increase taskefficiency and (potentially) achieve balance among their work, family, and personal obligations. Free fitness regimens offered on YouTube and Instagram by certified professionals provide enthusiasts with the ability to engage in fitness and sport participation in the comfort of their homes or workplace, without the need to spend extra time and money to attend a physical gym. Furthermore, virtual coaching, advice, and personal training platforms now allow sport participants and fitness enthusiasts to receive feedback and guidance on the go and at their convenience. Therefore, future work should investigate whether the portability of these services has allowed consumers to be more efficient in meeting their fitness goals or balancing time obligations for fitness and health with those related to their career or home life.

Finally, scholarship in this area could also draw attention to the opportunities for social entrepreneurship imbedded in fitness and lifestyle entrepreneurship. Scholarship has already identified that fitness and sport for public health are closely related to happiness, achievement, and longevity of life (Heinze et al. 2016). Naturally, there is a range of social benefits these technologies could engender beyond those related to economic gain. By furthering access to and knowledge of sport participation and fitness, sport and fitness entrepreneurs can play a central role in making societies healthier and happier. Lifestyle entrepreneurship shares a close conceptual relationship with social entrepreneurship, as the rejection of traditional economic motivations is an important aspect of lifestyle entrepreneurship (Ateljevic and Doorne 2000). Future work could thus advance the discussion of social and lifestyle entrepreneurship by exploring the centrality of lifestyle entrepreneurs to the social entrepreneurship landscape. Doing so may provide clues about how central lifestyle and fitness entrepreneurs to generating what Porter and Kramer (2011) term 'shared value' - using business activity and innovative methods to create concurrent economic and social value. With traditional models of capitalism under attack from those who perceive business objectives as deleterious to social and environmental issues, shared value 
provides a route forward whereby social and economic interests can be reconciled within a single, for-profit business model. ${ }^{1}$

\section{References}

Antoncic, B., \& Hisrich, R. D. (2003). Clarifying the intrapreneurship concept. Journal of Small Business and Enterprise Development, 10(1), 7-24.

Ateljevic, I., \& Doorne, S. (2000). 'Staying within the fence': Lifestyle entrepreneurship in tourism. Journal of Sustainable Tourism, 8(5), 378-392.

Bozek, P., Hall, T., Westcott, T., Marchello, M., Li, P., \& Young, A. (2017). New Frontiers for distribution of sports content. IHS Markit special report. Retrieved 10 April 2019 from https://corp.kaltura.com/wpcontent/uploads/2018/05/IHSM-white-paper-New-Frontiers-for-Distribution-of-Sports-Content1.pdf.

Dean, T. J., \& McMullen, J. S. (2007). Toward a theory of sustainable entrepreneurship: Reducing environmental degradation through entrepreneurial action. Journal of Business Venturing, 22(1), 50-76.

Drucker, P. (1985). Innovation and entrepreneurship: Practice and principles. New York, NY: Harper \& Row.

Ferreira, J., Fernandes, C., Ratten, V., \& Miragaia, D. (2020). Interactions between financial efficiency and sports performance. Journal of Entrepreneurship and Public Policy, 8(1), 84-102.

Goldsby, M. G., Kuratko, D. F., \& Bishop, J. W. (2005). Entrepreneurship and fitness: An examination of rigorous exercise and goal attainment among small business owners. Journal of Small Business Management, 43(1), 78-92.

Huertas González-Serrano, M., Jones, P., \& Llanos-Contrera, O. (2020). An overview of sport entrepreneurship field: A bibliometric analysis of the articles published in the web of science. Sport in Society, 23(2), 296-314.

Hayduk, T., \& Walker, M. (2018). Mapping the strategic factor market for sport entrepreneurship. International Entrepreneurship and Management Journal, 14(3), 705-724.

Heinze, K. L., Banaszak-Holl, J., \& Babiak, K. (2016). Social entrepreneurship in communities: Examining the collaborative processes of health conversion foundations. Nonprofit Management and Leadership, 26(3), 313-330.

Hemme, F., Morais, D. G., Bowers, M. T., \& Todd, J. S. (2017). Extending sport-based entrepreneurship theory through phenomenological inquiry. Sport Management Review, 20(1), 92-104.

Henderson, J. (2002). Building the rural economy with high-growth entrepreneurs. Economic Review-Federal Reserve Bank of Kansas City, 87(3), 45-75.

Henricks, M. (2002). Not just a living: The complete guide to creating a business that gives you a life. New York, NY: Basic Books.

Hess, F. M. (2007). The case for educational entrepreneurship: Hard truths about risk, reform, and reinvention. Phi Delta Kappan, 89(1), 21-30.

Heywood, L. (2015). The CrossFit sensorium: Visuality, affect and immersive sport. Paragraph, 38(1), 20-36.

Jones, G. J., Edwards, M. B., Bocarro, J. N., Bunds, K. S., \& Smith, J. W. (2017a). An integrative review of sport-based youth development literature. Sport in Society, 20(1), 161-179.

Jones, P., \& Jones, A. (2014). Attitudes of sports development and sports management undergraduate students towards entrepreneurship: A university perspective towards best practice. Education + Training, 56(8/9), $732-716$.

Jones, P., Jones, A., Williams-Burnett, N., \& Ratten, V. (2017b). Let's get physical: Stories of entrepreneurial activity from sports coaches/instructors. International Journal of Entrepreneurship and Innovation, 18(4), 219-230.

Jones, P., Ratten, V., Klapper, R. \& Fayolle, A. (2019) Entrepreneurial identity and context: Current trends and an agenda for future research, International Journal of Entrepreneurship and Innovation, 20(1), 3-7

Kramer, M. R., \& Porter, M. (2011). Creating shared value. Harvard Business Review, 89(1/2), 62-77.

Lerner, J (2010). Innovation, Entrepreneurship and financial market cycles. OECD Science, Technology and Industry Working Papers, 2010/03. OECD publishing. https://doi.org/10.1787/5kmjp6nt8rr8-en.

\footnotetext{
${ }^{1}$ For example, Toms shoes donates one pair of shoes to a child in a developing nation for every pair purchased by retail consumers. This approach was a central goal of the firm's business strategy from day one, and as such, the firm has managed the growth of manufacturing, distribution, and financial operations with that consideration at the forefront. Toms' competitors (Nike, Adidas, New Balance, Vans, etc.) cannot follow suit because doing so would require a complete overhaul of the firm's operational structures and protocols.
} 
Matsuno, K., Mentzer, J. T., \& Özsomer, A. (2002). The effects of entrepreneurial proclivity and market orientation on business performance. Journal of Marketing, 66(3), 18-32.

Minniti, M. (2010). Female entrepreneurship and economic activity. The European Journal of Development Research, 22(3), 294-312.

Miragaia, D., Ferreira, J., Carvalho, A. \& Ratten, V. (2019), Interactions between financial efficiency and sports performance: Data for a sustainable entrepreneurial approach of European professional football clubs, Journal of Entrepreneurship and Public Policy, 8(1) 84-102.

Pedersen, P. M., \& Thibault, L. (2018). Contemporary sport management. Champaign, IL: Human Kinetics.

Peters, M., Frehse, J., \& Buhalis, D. (2009). The importance of lifestyle entrepreneurship: A conceptual study of the tourism industry. Pasos, 7(2), 393-405.

Ratten, V. (2010). Developing a theory of sport-based entrepreneurship. Journal of Management \& Organization, 16(4), 557-565.

Ratten, V. (2012). Sports entrepreneurship: towards a conceptualisation, International Journal of Entrepreneurial Venturing 4(1), 1-17.

Ratten, V. (2015). Athletes as entrepreneurs: the role of social capital and leadership ability, International Journal of Entrepreneurship and Small Business 25(4), 442-455.

Ratten, V. (2019). Sports technology and innovation. New York: Palgrave.

Ratten, V. (2011). Sport-based entrepreneurship: Towards a new theory of entrepreneurship and sport management. International Entrepreneurship and Management Journal, 7(1), 57-69.

Ratten, V., \& Ferreira, J. (2017). Entrepreneurship, innovation and sport policy: Implications for future research. International Journal of Sport Policy and Politics, 9(4), 575-577.

Ratten, V., \& Ferreira, J. J. (Eds.). (2016). Sport Entrepreneurship and Innovation. Abingdon-on-Thames. UK: Taylor \& Francis.

Ratten, V., \& Jones, P. (2018). Future research directions for sport education: Toward an entrepreneurial learning approach. Education + Training, 60(5), 490-499.

Ratten, V., \& Miragaia, D. (2020). Entrepreneurial passion amongst female athletes. Journal of Small Business \& Entrepreneurship, 32(1), 59-77.

Rehman, L., \& Frisby, W. (2000). Is self-employment liberating or marginalizing? The case of women consultants in the fitness and sport industry. Journal of Sport Management, 14(1), 41-62.

Saxton, T. (2016). Olympics a, chance to showcase innovation, Entrepreneurship. Huffington Post. Retrieved 11 April 2019 from https://www.huffpost.com/entry/olympics-a-chance-to-show b 11566218

Schumpeter, J. (1934). Capitalism, socialism, and democracy. New York, NY: Harper \& Row.

Shapero, A., \& Sokol, L. (1982). The social dimensions of entrepreneurship. Encyclopedia of Entrepreneurship, 72-90.

Sheingate, A. D. (2003). Political entrepreneurship, institutional change, and American political development. Studies in American Political Development, 17(2), 185-203.

Smith, A. C., \& Westerbeek, H. M. (2007). Sport as a vehicle for deploying corporate social responsibility. Journal of Corporate Citizenship, 25, 43-54.

Spilling, O. R. (1996a). The entrepreneurial system: On entrepreneurship in the context of a mega-event. Journal of Business Research, 36(1), 91-103.

Spilling, O. R. (1996b). Mega event as strategy for regional development the case of the 1994 Lillehammer winter Olympics. Entrepreneurship \& Regional Development, 8(4), 321-344.

Williams, J., \& Chinn, S. J. (2010). Meeting relationship-marketing goals through social media: A conceptual model for sport marketers. International Journal of Sport Communication, 3(4), 422-437.

Publisher's note Springer Nature remains neutral with regard to jurisdictional claims in published maps and institutional affiliations. 